\title{
Factors associated with food choices among elderly: a scoping review
}

\section{Fatin Izzaty Mohd Shahrin ${ }^{1}$, Noraida Omar ${ }^{1,2^{*}}$, Zulfitri 'Azuan Mat Daud ${ }^{1} \&$ Nor Fadhlina Zakaria ${ }^{3}$}

${ }^{1}$ Department of Nutrition and Dietetics, Faculty of Medicine and Health Sciences, Universiti Putra Malaysia, Selangor, Malaysia; ${ }^{2}$ Malaysian Research Institute on Ageing (MyAgeing), Universiti Putra Malaysia, Selangor, Malaysia; ${ }^{3}$ Department of Medicine, Faculty of Medicine and Health Sciences, Universiti Putra Malaysia, Selangor, Malaysia

\begin{abstract}
Introduction: The aging population is a matter of global concern. Age-related physiological, pathological, psychosocial, economic, cultural and environmental changes are common and may greatly influence the quality of life of the elderly. The aim of this review was to explore the determinants and motivations that drive the elderly in making food choices. Methods: The search strategy of this literature review used the PRISMA protocol. Potential literature that was related to food choices was identified using two different combinations of keywords and two major electronic search engines, namely Pubmed and Science Direct. The articles that were selected for this review had to be in the English language, open-accessed and published between January 2007 and December 2017. Results: From a search of 1398 articles, 15 articles (seven quantitative and eight qualitative) were identified that were related to food choices among the elderly. The key factor that determined food choices among the elderly population was identified to be health. Others included convenience, sensory appeal, price, early food experience and more. The limitations of these studies that were reported were the small sample size and the reliance on self-reporting. The conclusions that were drawn were for specific groups that were studied in this review should be extrapolated or generalised with caution. Conclusion: Strategies for intervention programmes should be undertaken in collaboration with health professionals, researchers, policymakers, and the food industry. Future research is needed in the elderly who have chronic diseases, are dependent or who have disabilities.
\end{abstract}

Keywords: Food choice, food intake, elderly, nutrition, scoping review

\section{INTRODUCTION}

The aging population is a matter of global concern. The elderly, by definition, are those aged $\geq 60$ years. In $2017,13 \%$ of the global population aged $\geq 60$ years was approximately 962 million people, with the highest percentage (25\%) to be found in Europe. The world population of the elderly is forecast to be 1.4 billion in 2030, increasing to 2.1 billion in 2050 and to 3.1 billion in 2100 (UN DESA, 2017).

Age-related physiological, pathological, psychosocial, economic and cultural

\footnotetext{
*Corresponding author: Noraida Omar, PhD

Department of Nutrition and Dietetics, Faculty of Medicine and Health Sciences,

Universiti Putra Malaysia, 43400 UPM Serdang, Selangor, Malaysia

Tel: +6089472463; Fax: 03-89426769; E-mail: noraidaomar@upm.edu.my

doi: https:/ / doi.org/10.31246/mjn-2018-0133
} 
environmental changes (Rozin, 2006; Sharpe, Huston \& Finke, 2003) are common and may greatly influence the quality of life of the elderly. This complex phenomenon, interlaced with several socio-demographic factors such as gender (Wardle et al., 2004) and religion (Asma et al., 2010) can influence food choices and preferences (Rolls, 1999). Changes in food choices may have adverse effects on the energy and macronutrient intake and which in turn may eventually impact or aggravate nutrition-related illness, body weight, body composition, disability and the quality of life (Rolls, 1999).

The determinants of food choice in the elderly, as shown by previous studies, include the decline in chemosensory system sensitivity (i.e. in taste and smell) (Rolls, 1999), loss of appetite (Shatenstein et al., 2013) and life course events such as parental influence, early adult events and new health diagnoses during aging (Pucciarelli \& Thomas, 2011). The other factors that contribute to food choices are, inter alia, taste, convenience, cost, nutritional knowledge, health status and food accessibility (Ree, Riediger \& Moghadasian, 2008; Gunsam \& Murden, 2007). The understanding of these factors in influencing food choices is still unclear, limited and requires investigation (Gunsam \& Murden, 2007). Brownie \& Coutts (2013) stated that knowledge on how available dietary guidelines of food intake recommendations can be applied to food choices and daily life for the elderly is limited. Hence, the aim of this review is to explore the determinants and motivations of the elderly in their healthy food choices.

\section{METHODS}

The search strategy was undertaken according to the Preferred Reporting Items for Systematic and Meta-Analyses
(PRISMA) Statement Protocol (Moher et al., 2009), as shown in Figure 1. The electronic search engines namely Pubmed and Science Direct were used to identify potential literatures that were related to food choices. Two different combinations of keywords that were used in order to locate studies that were related to food choices were "food choice and elderly" and "food choice or elderly". The articles that were obtained in the identification step were then subjected to screening where duplicated articles were discarded and abstracts were examined to identify articles that were relevant to the research question of this review. The eligibility criteria that were adopted to accept the articles for this review, were as follows: (1) the article was written in the English language and was openaccessed; (2) publications for the period January 2007 to December 2017; (3) the definition of the elderly population by age was according to the country of origin and (4) the articles had explored factors related to food choices among older people. The exclusion criteria were articles with other age ranges instead of elderly subjects and informal narrative or reviews on food choices.

\section{RESULTS}

The identification step retrieved 1,398 publications by using the search engines mentioned and the two different combinations of keywords. The unrelated studies and duplicates were then removed and 1,148 articles were examined thoroughly for relevant abstracts. This procedure resulted in 41 full-text articles that were reviewed for eligibility for inclusion in the final review. Finally, 15 articles that met the inclusion criteria were summarised and tabulated by using the key concepts and themes of the studies. The outcomes were categorised into two research designs: 

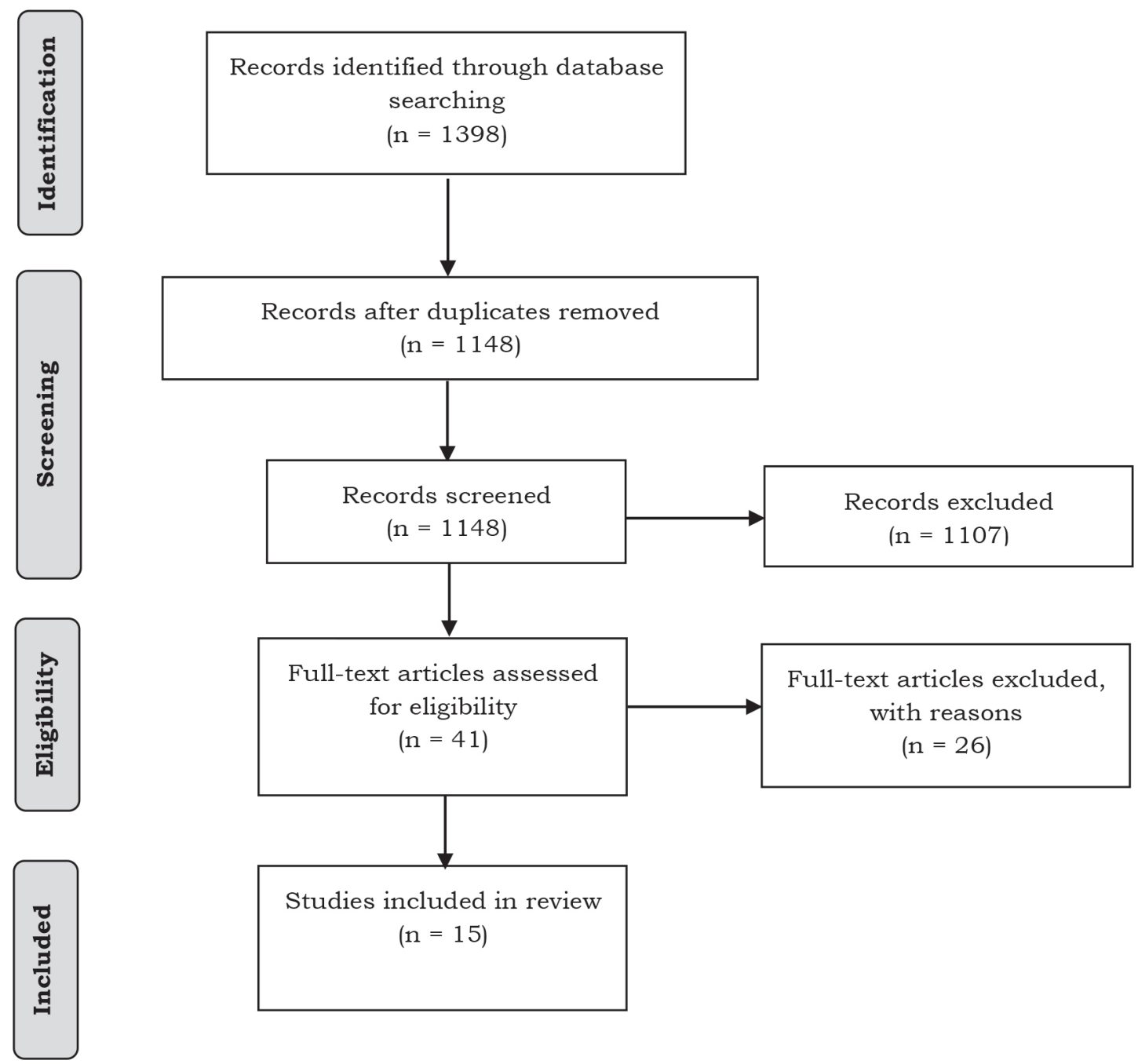

Figure 1. PRISMA flow chart illustrating the selection process of articles for this scoping review.

seven quantitative and eight qualitative types of research as presented in Table 1 and Table 2, respectively.

Table 1 indicates the summary of factors that are associated with food choices among elderly. Similar food choice factors were found repeatedly in various studies. These are health, taste, food access, body weight concern, nutritional knowledge, price, sensory appeal, and convenience. The themes that emerged from the qualitative studies are reported in Table 2 and they are food habits, social and economic circumstances, healthiness of the food and food access.

\section{DISCUSSION}

To the best of our knowledge, this is the first scoping review that has investigated the various factors that influence the food choices of the elderly, after a supporting research article that was published about 24 years ago by Herne 


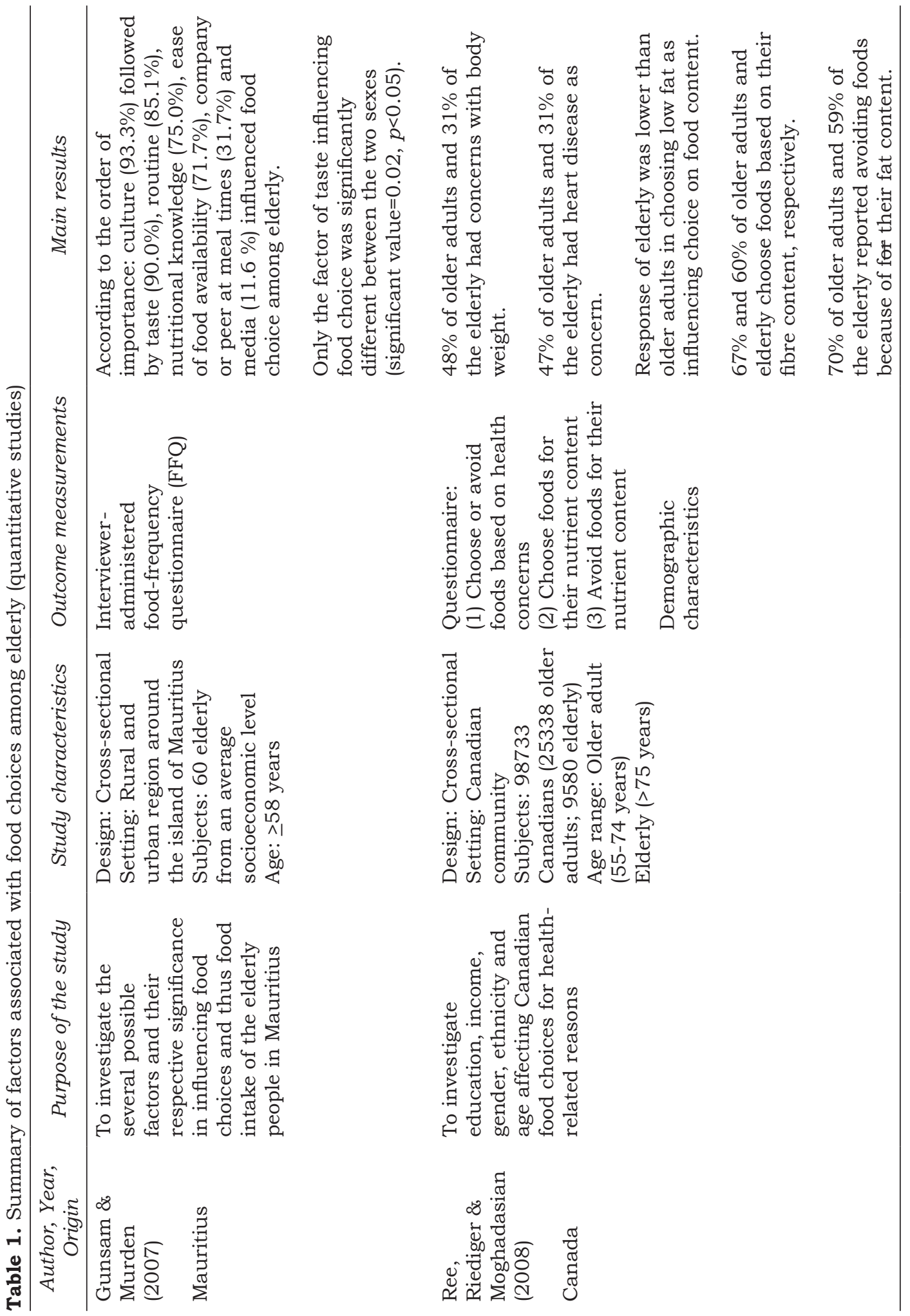




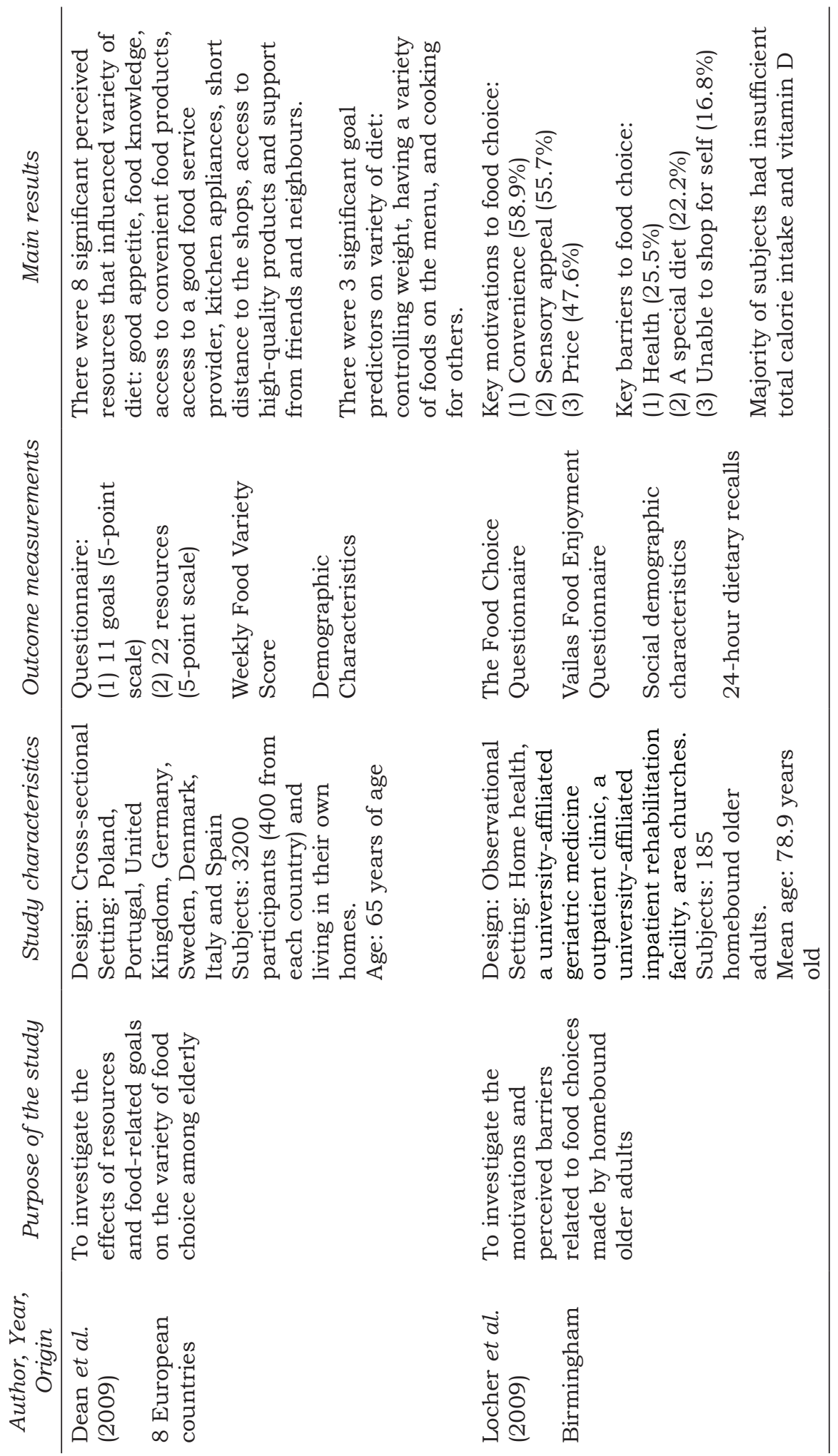




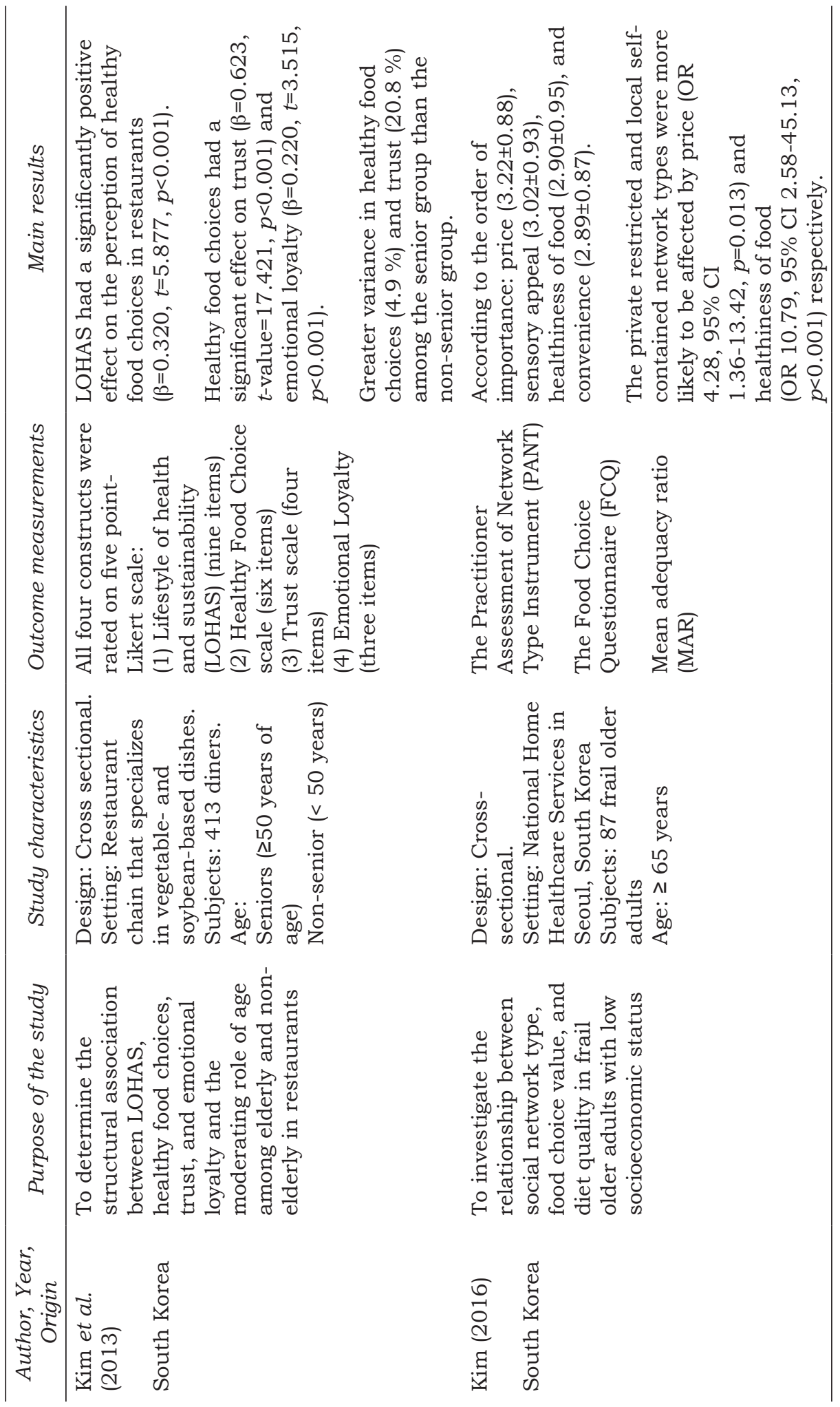




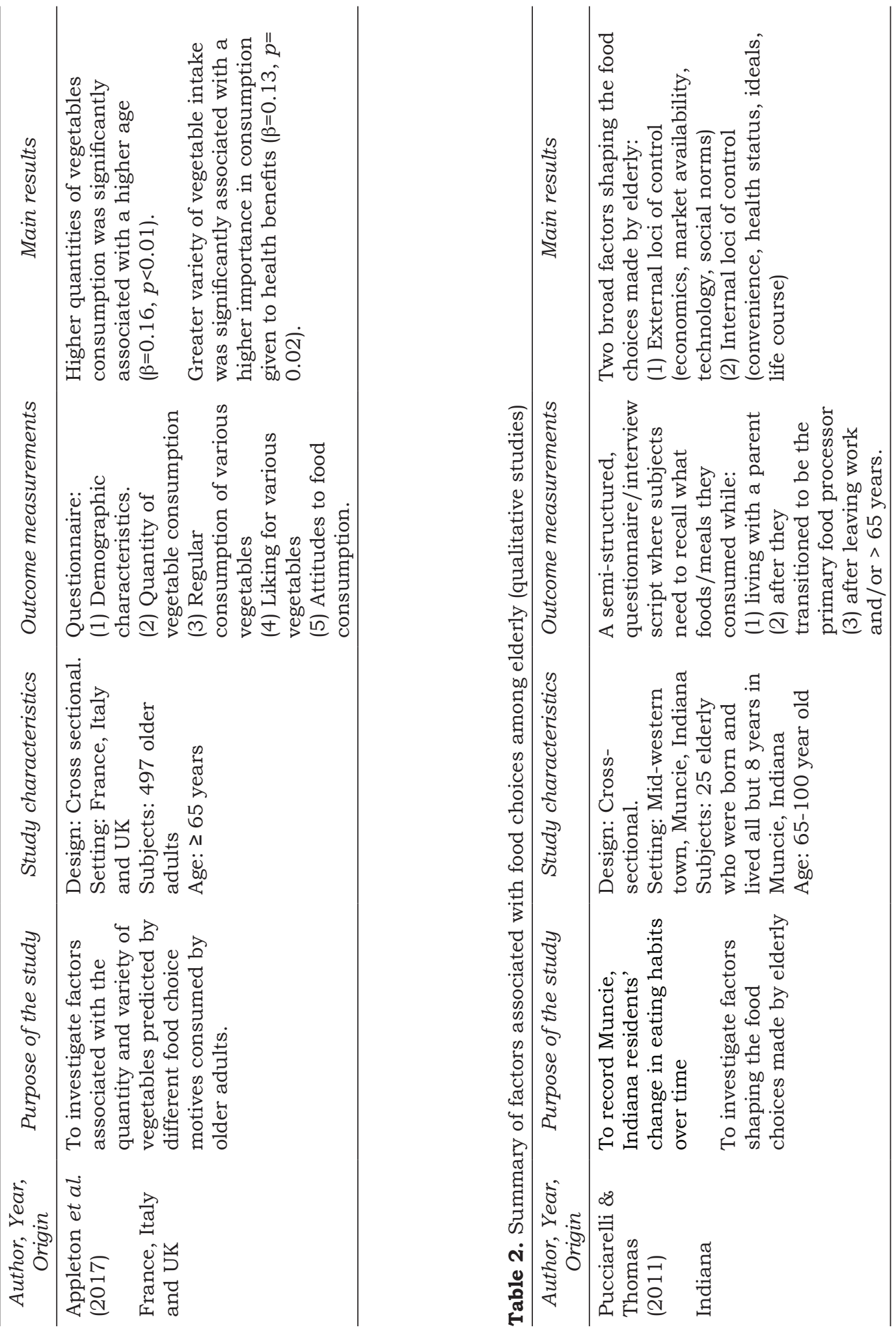




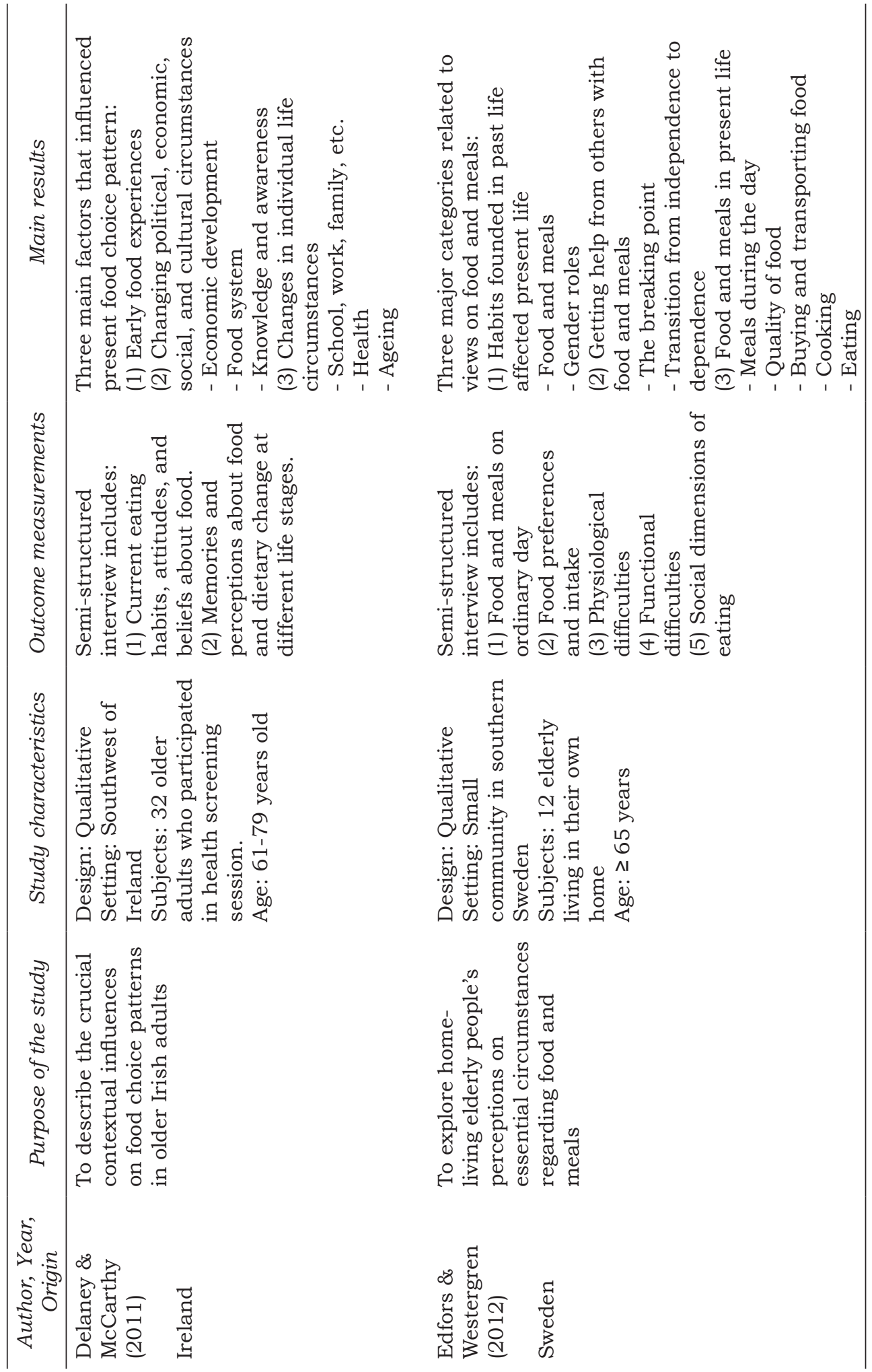




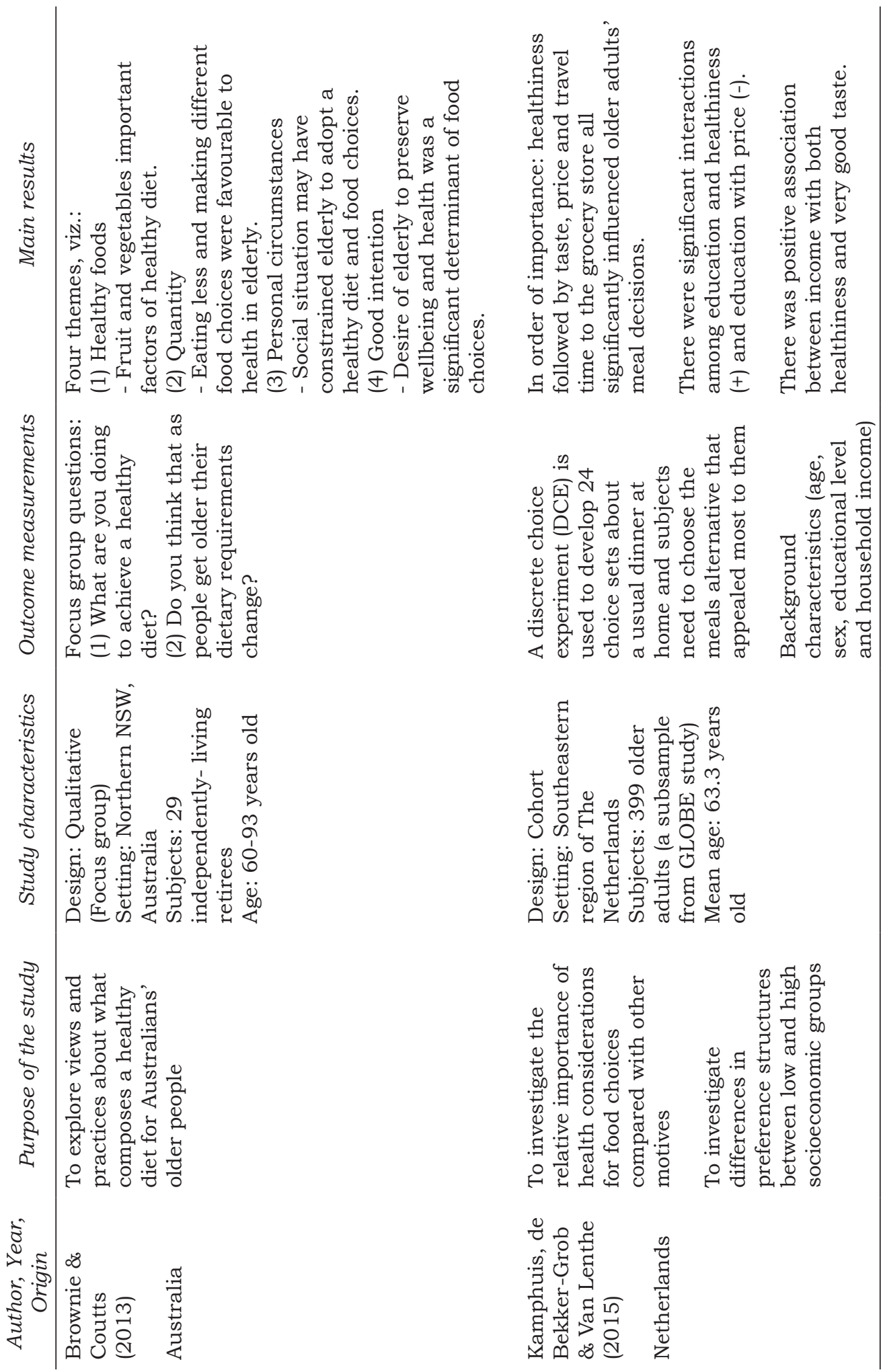




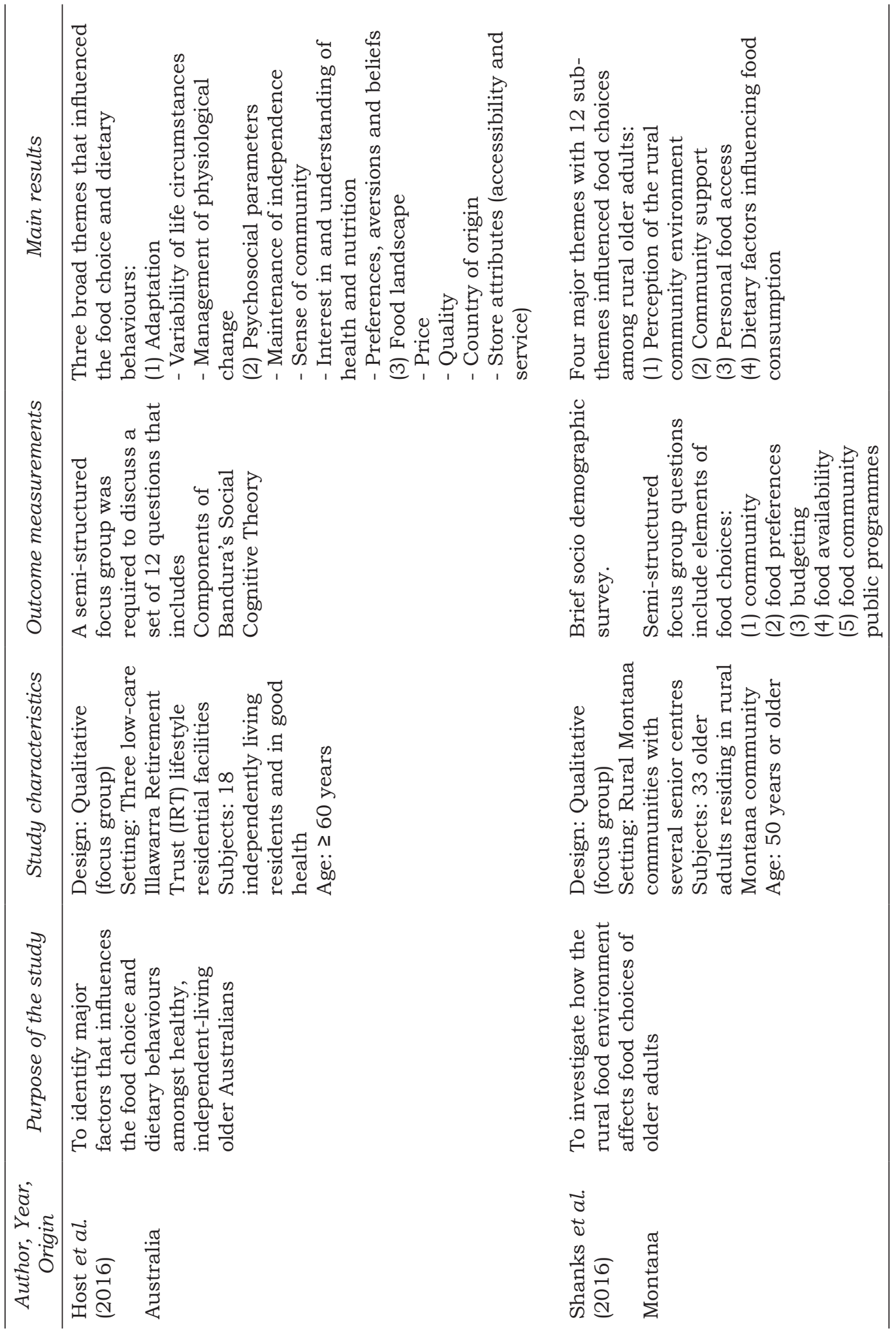




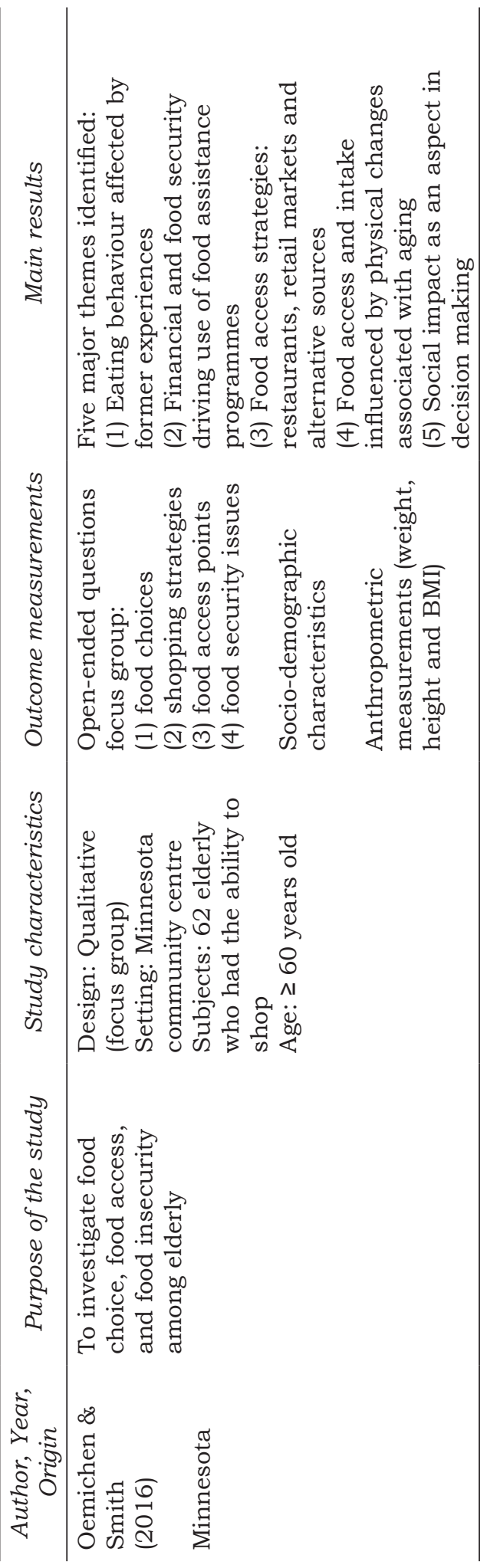


(1995). A small number of research studies were conducted on elements affecting food choices in the elderly, and only 15 relevant studies that were published between 2007 and 2017 were retrieved. Therefore, this review is a key step in conveying to healthcare professionals, future researchers, policymakers and the food industry itself, the impact of food choices among the elderly in different settings.

This scoping review should contribute to the small but growing body of literature predominantly from Europe followed by North America, Asia, Australia and Africa, that examines food choices among the elderly. The majority of the studies (9 of 15) identified health as the most important factor that determined the food choices among the elderly. Ree et al. (2008) revealed that the health-conscious group was mainly middle-aged and older adults who tended to select food wisely for different reasons related to health such as disease prevention, disease management, or maintaining physical independence. It has been observed that the elderly readily modify their food habits and are willing to fight the urge of eating their favourite foods as instructed by their doctors (Shanks et al., 2016). This has been categorised as internal indicators that shape the food choice of older people (Pucciarelli \& Thomas, 2011). The lowering of fat and cholesterol intake with healthier food choices in order to meet health goals were among the changes specifically made by the elderly (Delaney \& McCarthy, 2011; Pucciarelli \& Thomas, 2011; Host et al., 2016). A significant association was found between vegetable intake of different varieties and the higher importance given to health benefits (Appleton et al., 2017) as the elderly assumed that fruits and vegetables were important parts of a healthy diet (Brownie \& Coutts, 2013).
A study by Kim
(2016) showed

that persons who did not have local kinfolk, few nearby friends, low levels of community contacts and infrequent contact with at least one relative, and the frail elderly were, surprisingly, concerned about the healthiness of food. An earlier study conducted by Kim et al. (2013) showed the strong impact of the lifestyle of health and sustainability (LOHAS) on healthy food choices within a group of seniors. This should trigger health-oriented marketers to treat the elderly as a separate market segment.

In contrast, homebound elderly adults chose health as the major perceived barrier to food intake as per participants' meal preference (Locher et al., 2009). Gender also played a role as women were seen to be more likely to select or discard foods due to health reasons and nutrient content (Ree et al., 2008). Highly educated and higher income older adults rated a healthy meal to be a more important consideration in making meal decisions (Kamphuis, de Bekker-Grob \& Van Lenthe, 2015).

Convenience was the second most common consideration that determined food choices for older people. Locher et al. (2009) reported that convenience was the most important perceived motivation related to food selection whilst it was the fourth consideration in the report by Kim (2016) after the price, sensory appeal, and healthiness of food. Convenience meant the ease of food preparation (Pucciarelli \& Thomas, 2011), and convenient transport. A short distance to go to the shops provided more varied dietary choices (Dean et al., 2009).

Most of the studies that we examined reported similar limitations. The first limitation was the small sample size (Locher et al., 2009; Kim, 2016; Appleton et al., 2017; Delaney \& McCarthy, 2011; Edfors \& Westergren, 2012; Host et al., 2016; Shanks et al., 2016). Thus, future studies with a larger sample sizes will benefit the complexity of food choices 
in the elderly population. Secondly, the dependence on self-reporting inevitably results in inaccuracies and biases (Locher et al., 2009; Kim, 2016; Appleton et al., 2017; Pucciarelli \& Thomas, 2011; Host et al., 2016). There were also unmeasured confounding factors that might have had an effect on the study results of Kim (2016) and Kamphuis et al. (2015). Lastly, as the studies in this review were focused only on homebound older adults (Locher et al., 2009), Korean seniors in restaurants (Kim et al., 2013), frail older adults (Kim, 2016), seniors from Midwestern town (Pucciarelli \& Thomas, 2011), elderly in rural and urban environment (Delaney \& McCarthy, 2011) and older adults from a senior centre (Host et al., 2016), extrapolation of findings to other ethnic groups and geographical areas may not always be valid. Further cross-cultural studies are necessary to apply findings in groups across geographical borders.

Nevertheless, the findings and conclusions of this review have vital relevance to clinical practice and implementation in the area of nutrition. Health promotion interventions and policies with a multifactorial approach that are aimed to promote a healthy diet, food modifications and eating behaviour (Locher et al., 2009) of the elderly should take into account the potential influence of health, interpersonal and social issues to them (Gunsam \& Murden, 2007). Explicit strategies on awareness, health messages (Delaney \& McCarthy, 2011), affordable and easy meal preparation will have a greater chance to be put into practice by the elderly (Pucciarelli \& Thomas, 2011) to prevent and manage chronic diseases. Furthermore, the involvement of caregivers in medical nutrition therapy for the elderly (Locher et al., 2009) and raising the awareness of age-adjusted nutrient targets through media campaigns (Brownie \& Coutts, 2013) may help to change the behaviour of the elderly to make them realise the importance of food choices. Health professionals need to be aware of existing information regarding social network of elderly with local family and/ or friends and neighbours. This may help in deciding suitable interventions to develop healthy food choice values especially among the elderly with few community contacts (Kim, 2016).

\section{CONCLUSION}

This review of seven quantitative and eight qualitative studies conducted in different continents has given new insights on food choices among the elderly. The health domain was the most commonly reported factor that influenced food choices besides convenience, price, sensory appeal, among others. Small sample size, reliance on self-reporting and the inability to make generalisations, were the most important limitations of this review. New strategies for intervention programs should be undertaken by a joint force of health professionals, researchers, policymakers and the food industry. Future research in the elderly who have developed a particular chronic disease, and those who are independent or with a disability is needed.

\section{Acknowledgments}

This study was funded by the Putra Grant-Putra Graduate Initiative (IPS) of Universiti Putra Malaysia.

\section{Authors' contributions}

FIMS, designed and conceptualised the study and search strategy, undertook the analyses and drafted and edited the manuscript; NO, advised on the analysis, description and classifying the study and reviewed the manuscript; ZAMD, and co-supervisors reviewed the manuscript; NFZ and co-supervisors reviewed the manuscript.

\section{Conflict of interest}

The authors declare that they have no competing interests. 


\section{References}

Appleton KM, Dinella C, Spinelli S, Morizet D, Saulais L, Hemingway A, Monteleone E, Depezay L, Perez-Cueto FJA \& Hartwell H (2017). Consumption of a high quality and a wide variety of vegetables are predicted by different food choice motives in older adults from France, Italy and the UK. Nutrients 9(923):1-17.

Asma A, Nawalyah AG, Rokiah MY \& Mohd Nasir MT (2010). Comparison of food choice motives between Malay husbands and wives in an urban community. Malaysian J Nutr 16(1):6981.

Brownie S \& Coutts R (2013). Older Australians' perceptions and practices in relation to a healthy diet for old age: A qualitative study. The Journal of Nutrition, Health \& Ageing 17(2):125129.

Dean M, Raats MM, Grunert KG, Lumbers M \& The Food in Later Life Team (2009). Factors influencing eating a varied diet in old age. Public Health Nutrition 12(2):2421-2427.

Delaney M \& McCarthy M (2011). Food choice and health across the life course: A qualitative study examining food choice in older Irish adults. Journal of Food Products Marketing 17(2-3):114-140.

Edfors E \& Westergren A (2012). Home-living elderly people's views on food and meals. Journal of Aging Research 2012:14-18.

Gunsam PP \& Murden S (2007). Factors influencing food choice in the elderly Mauritian population. UoM Research Journal 13A:179-191.

Herne S (1995). Research on food choice and nutritional status in elderly people: a review. British Food Journal 97(9):12-29.

Host A, McMahon AT, Walton K \& Charlton K (2016). 'While we can, we will': Exploring food choice and dietary behavior amongst independent older Australians. Nutrition \& Dietetics 73:463-473.

Kamphuis CBM, de Bekker-Grob EW \& Van Lenthe FJ (2015). Factors affecting food choices of older adults from high and low socioeconomic groups: a discrete choice experiment. American Journal Clinical Nutrition 101(4):768-74.

Kim CO (2016). Food choice patterns among frail older adults: The associations between social network, food choice values, and diet quality. Appetite 96:116-121.

Kim MJ, Lee CK, Kim WG \& Kim JM (2013). Relationships between lifestyle of health and sustainability and healthy food choices for seniors. International Journal of Contemporary Hospitality Management 25(1):558-576.
Locher JL, Ritchie CS, Roth DL, Sen B, Vickers KS \& Vailas LI (2009). Food choice among homebound older adults: A motivations and perceived barriers. The Journal of Nutrition, Health \& Ageing 13(8):659-664.

Moher D, Liberati A, Tetzlaff J, Altman DG \& PRISMA Group (2009). Preferred Reporting Items for Systematic Reviews and MetaAnalyses: The PRISMA Statement. PLoS Med 6(7):e1000097.

Oemichen M \& Smith C (2016). Investigation of the food choice, promoters and barriers to food access issues, and food insecurity among low-income, free-living Minnesotan seniors. Journal of Nutrition Education and Behavior 48(6):397-404.

Pucciarelli D \& Thomas A (2011). Determinates that influence food consumption among older members of a Midwest community. Food and Nutrition Sciences 2:1018-1026.

Ree M, Riediger N \& Moghadasian MH (2008). Factors affecting food selection in Canadian population. European Journal of Clinical Nutrition 62:1255-1262.

Rolls BJ (1999). Do chemosensory changes influence food intake in elderly? Physiol Behav 66:193-199.

Rozin P (2006). The integration of biological, social, cultural and psychological influences on food choice. In $\mathrm{R}$ Shepherd \& $\mathrm{M}$ Raats (eds). The psychology of food choice (pp. 19-39). CABI Press, Oxfordshire, UK.

Shanks CB, Haack S, Tarabochia D, Bates K \& Christenson L (2016). Factors influencing food choices among older adults in the rural western USA. Journal of Community Health 42(3):511-521.

Sharpe DL, Huston SJ \& Finke MS (2003). Factors affecting nutritional adequacy among single elderly women. Fam Econ Nutr Rev 15:74-82.

Shatenstein B, Gauvin L, Keller H, Richard L, Gaudreau P, Giroux F, Gray-Donald K, Jabbour M, Morais JA \& Payette H (2013). Baseline determinants of global diet quality in older men and women from the NuAge cohort. $J$ Nutr Health Aging 17:419-425.

UN DESA (2017). World Population Prospects: The 2017 Revision, Key Findings and Advance Tables. Working Paper No. ESA/P/WP/248.

Wardle J, Haase AM, Steptoe A, Nillapun M, Jonwutiwes K \& Bellisle F (2004). Gender differences in food choice: the contribution of health beliefs and dieting. Ann Behav Med 27:107-116. 